\title{
1 Mutations in efflux pump Rv1258c (Tap) cause resistance to pyrazinamide and other
}

\section{2 drugs in M. tuberculosis}

3

4 Jiayun Liu ${ }^{1,2}$, Wanliang Shi $^{1}$, Shuo Zhang ${ }^{1}$, Gail Cassell $^{3}$, Dmitry A. Maslov ${ }^{4}$, Kirill V. Shur ${ }^{4}$, Olga B. Bekker ${ }^{4}$, 5 Valery N. Danilenko ${ }^{4},{\text { Xiaoke } \mathrm{Hao}^{2 *}, \text { Ying Zhang }}^{1 *}$

71 Department of Molecular Microbiology and Immunology, Bloomberg School of Public Health, Johns

8 Hopkins University, Baltimore, Maryland, USA

92 Department of Clinical Laboratory, Xijing Hospital, Fourth Military Medical University, Xi'an, China

103 Department of Global Health and Social Medicine, Harvard Medical School, Division of Global Health

11 Equity, Brigham and Women's Hospital, Boston, Massachusetts, USA.

124 Laboratory of Bacterial Genetics, Vavilov Institute of General Genetics, Gubkina str. 3, 119991, Moscow, 13 Russia

16 Running title: PZA and Other Drug Resistance Mediated by Efflux Pump Mutations

$19 *$ Corresponding author:

20 Prof. Xiaoke Hao

21 Email: haoxkg@fmmu.edu.cn

23 Prof. Ying Zhang

24 Email: yzhang@jhsph.edu 
27 Abstract

Although drug resistance in M. tuberculosis is mainly caused by mutations in drug activating enzymes or drug

targets, there is increasing interest in possible role of efflux in causing drug resistance. Previously, efflux genes

are shown upregulated upon drug exposure or implicated in drug resistance in overexpression studies, but the

role of mutations in efflux pumps identified in clinical isolates in causing drug resistance is unknown. Here we investigated the role of mutations in efflux pump Rv1258c (Tap) from clinical isolates in causing drug resistance in M. tuberculosis by constructing point mutations V219A, S292L in Rv1258c in the chromosome of M. tuberculosis and assessed drug susceptibility of the constructed mutants. Interestingly, V219A, S292L point mutations caused clinically relevant drug resistance to pyrazinamide (PZA), isoniazid (INH), and streptomycin (SM), but not to other drugs in M. tuberculosis. While V219A point mutation conferred a low level resistance, the S292L mutation caused a higher level of resistance. Efflux inhibitor piperine inhibited INH and PZA resistance in the S292L mutant but not in the V219A mutant. S292L mutant had higher efflux activity for pyrazinoic acid (the active form of PZA) than the parent strain. We conclude that point mutations in the efflux pump Rv1258c in clinical isolates can confer clinically relevant drug resistance including PZA and could explain some previously unaccounted drug resistance in clinical strains. Future studies need to take efflux mutations into consideration for improved detection of drug resistance in $M$. tuberculosis and address their role in affecting treatment outcome in vivo.

\section{INTRODUCTION}

Multidrug resistant (MDR) tuberculosis (MDR-TB), defined by resistance to at least two frontline drugs isoniazid and rifampin, poses a significant challenge to effective treatment and control of the disease. In 2015, there were at least 480,000 cases of MDR-TB and about $9.5 \%$ of MDR-TB cases were extensively drug resistant TB or XDR-TB (1). Drug resistance in the causative agent $M$. tuberculosis is mainly caused by mutations affecting enzymes involved in drug activation or by alterations or overexpression of drug targets (2). However, efflux pumps, which have been found to cause antibiotic resistance in many other bacteria (3) and 
¡3 also nontuberculous mycobacteria $(4,5)$ have only recently been shown to be involved in clinical drug

¡4 resistance in $M$. tuberculosis in the case of clofazimine and bedaquiline $(6,7)$.

55

The efflux protein Rv1258c, also called Tap or P55, was previously shown to be involved in resistance to different drugs in overexpression studies involving M. smegmatis and M. bovis BCG (8, 9). For example, overexpression of Rv1258c was shown to confer resistance to INH, rifampin, ethambutol, PAS, ethambutol in M. bovis BCG (9). Additionally, Jiang et al. showed that Rv1258c was overexpressed upon exposure to isoniazid (INH) and rifampin (RIF) in MDR-TB clinical isolates and hypothesized that its overexpression may cause drug resistance in clinical TB strains (10). Furthermore, various single nucleotide polymorphisms (SNPs) in different efflux pump genes Rv0194, Rv1217, Rv1258, Rv1273, Rv1877, Rv1250, and Rv2688 in XDR-TB clinical isolates were recently identified (11). However, the relevance of these SNPs in causing drug resistance in clinical strains has been unclear. In this study, we identified SNPs in the efflux gene Rv1258c (tap) from clinical isolates of $M$. tuberculosis and then evaluated the significance of the SNPs in causing clinically relevant drug resistance by introducing these point mutations into the genome of the isogenic strain of M. tuberculosis. We demonstrate that mutations (V219A, S292L) in efflux pump Tap Rv1258c identified in clinical strains can cause clinically relevant drug resistance in M. tuberculosis.

\section{MATERIALS AND METHODS}

Bacterial strains, plasmids and drugs. M. tuberculosis $\mathrm{H} 37 \mathrm{Ra}$ was grown at $37^{\circ} \mathrm{C}$ in Middlebrook $7 \mathrm{H} 9$ liquid medium or on 7H11 agar plates supplemented with $10 \%(\mathrm{v} / \mathrm{v})$ albumin-dextrose-catalase (ADC, Becton Dickinson, Sparks, MD, USA) plus 0.5\% (v/v) glycerol, 0.25\% (v/v) Tween 80. Plasmids p2NIL and pGOAL19 used in this study were obtained from Addgene (Cambridge, MA, USA). Isoniazid (INH), rifampicin, streptomycin (SM), ethambutol, pyrazinamide (PZA), levofloxacin, amikacin, cycloserine, p-aminosalicylic acid (PAS), clofazimine (CFZ), tetracycline, linezolid, clarithromycin, and piperine were purchased from Sigma-Aldrich (St Louis, MO, USA). The drugs were dissolved in DMSO and further diluted to obtain the 
desired concentrations in culture media for drug susceptibility testing (see below).

Construction of Rv1258c point mutation mutants by homologous recombination. $M$. tuberculosis mutants

were constructed by homologous recombination as described previously (12). Briefly, the Rv1258c gene was

amplified with its adjacent $1 \mathrm{~kb}$ fragment on both sides from $M$. tuberculosis genomic DNA and cloned into

p2NIL plasmid vector. Then, the mutated constructs Rv1258c V219A, S292L were obtained by QuikChange II

XL site-directed mutagenesis kit (Agilent, Santa Clara, CA, USA) with primers TPV219AF: 5'-

TTCGCCTGGAACCTGCGGGTATTGCGCACCC-3', TPV219AR:

5'-CCAGGCGAAGCGCAGCCCCTCGGCGATCCC-3', TPS292LR: 5'-

PacI site of p2NIL containing the mutant (V219A and S292L) version of the Rv1258c gene to form suicide delivery constructs. The suicide delivery plasmid DNA was subjected to $100 \mathrm{~mJ} / \mathrm{cm} 2$ of UV irradiation parameter $2.5 \mathrm{kV}, 1000 \Omega, 25 \mathrm{mF}$. The electroporated cells were added with $200 \mu \mathrm{l}$ 7H9-Tween 80 recovery any antibiotics and incubated at $37^{\circ} \mathrm{C}$ for $2-3$ weeks. A loopful of bacteria from the plates were resuspended in 1 $\mathrm{ml}$ of $1-\mathrm{mm}$ glass beads and $3 \mathrm{~mL}$ of 7H9/ADC/Tween 80 and vortexed vigorously. Serial dilutions were plated onto plates containing X-gal with and without sucrose at $2 \%(\mathrm{w} / \mathrm{v})$ and incubated for 4 weeks until the potential tuberculosis H37Ra. 
mutants and parent strain $M$. tuberculosis $\mathrm{H} 37 \mathrm{Ra}$ were grown in7H9/ADC/Tween 80 medium at $37^{\circ} \mathrm{C}$ for $2-3$

weeks (approximately $1 \times 10^{8}$ colony-formingunits $(\mathrm{CFU}) / \mathrm{ml}$ ) when they were diluted in serial 10 -fold dilutions and inoculated onto 7H11 agar plates containing different concentrations of drugs in triplicate. The following drug concentrations were used: $\mathrm{SM}(0.5,1,2,4,8 \mu \mathrm{g} / \mathrm{ml})$. INH $(0.125,0.25,0.5,1,2,4,8,16,32,64 \mu \mathrm{g} / \mathrm{ml})$, PZA (50, 100, 200, 400, 800, $1600 \mu \mathrm{g} / \mathrm{ml}, \mathrm{pH}$ 6.0), p-aminosalicylic acid (PAS) $(0.25,0.5,1,2,4,8,16,32,64$, $128 \mu \mathrm{g} / \mathrm{ml})$, rifampicin $(0.25,0.5,1,2,4 \mu \mathrm{g} / \mathrm{ml})$, ethambutol $(1,2,4,8,16 \mu \mathrm{g} / \mathrm{ml})$, levofloxacin $(0.25,0.5,1,2$, $4 \mu \mathrm{g} / \mathrm{ml})$, amikacin $(0.5,1,2,4,8 \mu \mathrm{g} / \mathrm{ml})$, cycloserine $(5,10,20,40,80 \mu \mathrm{g} / \mathrm{ml})$, clofazimine $(\mathrm{CFZ})(0.125,0.25$, $0.5,1,2 \mu \mathrm{g} / \mathrm{ml})$, tetracycline $(0.5,1,2,4,8,16,32,64,128 \mu \mathrm{g} / \mathrm{ml})$, linezolid $(0.25,0.5,1,2,4 \mu \mathrm{g} / \mathrm{ml})$, clarithromycin $(0.125,0.25,0.5,1,2 \mu \mathrm{g} / \mathrm{ml})$. The plates were incubated at $37^{\circ} \mathrm{C}$ in $5 \% \mathrm{CO}_{2}$ for $3-4$ weeks. The isoniazid/piperine combination study was performed on the Rv1258c V219A and S292L mutants with different concentrations of INH tested in the presence of increasing concentrations of piperine $(0,5,10,20,40 \mu \mathrm{g} / \mathrm{ml})$.

PZA uptake and accumulation experiments. Two-week-old cultures of Rv1258c V219A and S292L mutants M. tuberculosis H37Ra, grown in in7H9/ADC/Tween 80 medium, were harvested and the cell pellets were resuspended in $7 \mathrm{H} 9$ medium $(\mathrm{pH} 6.6)$ at $5 \times 10^{8}$ cells $/ \mathrm{ml}$. The PZA uptake and accumulation study was performed as described previously (13). Briefly, $\left[{ }^{14} \mathrm{C}\right] \mathrm{PZA}$, purchased from Vitrax (Placentia, CA, USA), was added to the cell suspensions to a concentration of $1 \mu \mathrm{Ci} / \mathrm{ml}$ and the cell mixtures were incubated at $37^{\circ} \mathrm{C}$. At different time points, $50 \mu \mathrm{l}$ portions were removed and washed with $1 \times \mathrm{PBS}$ buffer $(\mathrm{pH} 6.6)$ with $0.1 \mathrm{M} \mathrm{LiCl}$ by filtration on $0.45 \mu \mathrm{m}$-pore-size nitrocellulose filters by using a vacuum pump. The amount of radioactivity associated with the bacterial cells was determined by autoradiography and scintillation counting.

\section{RESULTS AND DISCUSSION}

\section{Identification of point mutations in Rv1258c from clinical isolates of $M$. tuberculosis and construction of}

Rv1258c point mutations in M. tuberculosis. To determine possible roles of efflux pumps in causing drug resistance, we performed database search for mutations in the efflux pump Rv1258c (Tap) among clinical 
31 isolates whose whole genome sequences are deposited in the PubMed NCBI database. A number of single

nucleotide polymorphisms (SNPs) were found in the Tap efflux gene Rv1258c (D23V, V219A, S292L) in

different clinical isolates of $M$. tuberculosis, which may affect the function of the efflux protein. This is

consistent with the identification of Rv1258c P369T and G391R in XDR-TB clinical isolates from sequenced genomes of M. tuberculosis strains from Pakistan (11).

To address the role of the identified point mutations in Rv1258c, we attempted to construct the point mutations D23V, V219A and S292L by site-directed mutagenesis by PCR and the altered mutant sequences were confirmed to be correct by DNA sequencing. We were able to successfully construct Rv1258c point mutations V219A and S292L, but not D23V (for unknown reasons) in M. tuberculosis H37Ra. It is worth noting that the constructed Rv1258c point mutation V219A and S292L mutant strains had no growth defect or altered morphology as seen in Rv1258c deletion mutant strain (9). Therefore, we evaluated the susceptibility of Rv1258c point mutation V219A and S292L mutants to various drugs as described below.

Rv1258c point mutations confer resistance to PZA, INH, and SM. The results of drug susceptibility testing showed that Rv1258c S292L mutant was more resistant to streptomycin, isoniazid, and pyrazinamide than the parent strain H37Ra (Table 1). However, Rv1258c V219A point mutation caused a lower level of resistance to the above drugs than the S292L mutation. It is noteworthy that while V219A mutation only caused a marginal level of INH resistance $(\mathrm{MIC}=0.125 \mu \mathrm{g} / \mathrm{ml}), \mathrm{S} 292 \mathrm{~L}$ mutation caused a very high level of INH resistance $(\mathrm{MIC}=32 \mu \mathrm{g} / \mathrm{ml})$ (Table 1). This latter finding is significant as it offers a possible alternative mechanism of INH resistance in addition to mutations in $\operatorname{kat} G(2,14)$ or $\operatorname{inh} A(15)$. Introduction of the V219A and S292L mutations in $M$. tuberculosis did not alter the susceptibility to other drugs including rifampicin, ethambutol, levofloxacin, amikacin, cycloserine, p-aminosalicylic acid (PAS), clofazimine (CFZ), tetracycline, linezolid and clarithromycin (Fig. 1-4, Table 1). Our finding that Rv1258c S292L point mutation conferred resistance to streptomycin and isoniazid is consistent with the previous observation of overexpression of Rv1258c (9). However, the Rv1258c S292L and V219A mutations did not alter susceptibility to other drugs such as 
tetracycline, RIF, EMB, CFZ, where previous studies have demonstrated that overexpression of Rv1258c could cause resistance to these drugs $(5,9,16)$. One possibility for such a discrepancy is that the point mutations at S292L and V219A cause differential binding to different drugs such that they have differential effects on causing selective drug resistance to some but not other drugs as seen in overexpression study of the wild type functional protein Rv1258c $(9,16)$.

Previous studies that evaluated drug resistance conferred by overexpression of Rv1258c did not test PZA, presumably because of the well-known problem with its susceptibility testing (17). Here, it is of interest to note that introducing the S292L point mutation in Rv1258c into the chromosome of M. tuberculosis conferred a high level of PZA resistance $(800 \mu \mathrm{g} / \mathrm{ml})$, whereas the V219A mutation caused a low level of PZA resistance (100$200 \mu \mathrm{g} / \mathrm{ml}$ ) (Fig. 3). Although PZA resistance is mostly caused by pncA mutations (18) and less commonly by rpsA (19), panD (20), and $\operatorname{clpC1}(21,22)$ mutations, some PZA-resistant $M$. tuberculosis strains without mutations in the above known genes do exist (23) (Zhang Y, unpublished). Recently, we have shown that overexpression of efflux proteins Rv0191, Rv3756c, Rv3008, and Rv1667c could all confer a low level PZA resistance in $M$. tuberculosis (24), indicating a role of efflux in PZA resistance. However, not all efflux pumps are involved in PZA resistance as overexpression of DrrAB in M. tuberculosis did not confer PZA resistance (Zhang Y, unpublished). Here it is worth noting that by constructing point mutations in the genome of the efflux pump gene Rv1258c, we were able to convincingly demonstrate that the S292L mutation is indeed causative of PZA resistance. This finding suggests that mutations in Rv1258c could be a potential new mechanism of PZA resistance in clinical isolates without known structural gene (pncA, rpsA, panD) mutations. Future studies are needed to determine how frequent such mechanism of PZA resistance mediated by mutations in Rv1258c occur in clinical isolates.

Piperine inhibits the INH and PZA resistance in the Rv1258c S292L mutant. Piperine is a known inhibitor of Rv1258c in M. tuberculosis (25). To determine if the S292L point mutation mediated higher level of resistance is due to elevated efflux activity of the Rv1258c S292L mutant protein, we tested if piperine could 
antagonize the INH and PZA resistance mediated by the Rv1258c S292L mutant protein. The piperine/INH or piperine/PZA combination study showed that piperine reduced both INH and PZA resistance or increased INH and PZA susceptibility in the Rv1258c S292L mutant M. tuberculosis strain, but not in the V219A mutant strain (Fig. 5). The results indicate that the higher level of INH or PZA resistance in the Rv1258c S292L mutant is caused by higher efflux activity of the mutant protein that could be inhibited by piperine.

PZA-resistant Rv1258c S292L mutant accumulates less drug POA. It has been shown that $\left[{ }^{14} \mathrm{C}\right] \mathrm{PZA}$ is converted to $\left[{ }^{14} \mathrm{C}\right] \mathrm{POA}$ in $M$. tuberculosis and accumulates in the cell to some extent due to a weak efflux of POA (13). To determine if Rv1258c V219A and S292L mutants, which are confirmed to be PZA-resistant in susceptibility testing (Fig. 3), can pump $\left[{ }^{14} \mathrm{C}\right] \mathrm{PZA}$ out of the cell more effectively, we performed the $\left[{ }^{14} \mathrm{C}\right] \mathrm{PZA}$ uptake experiment comparing the amount of $\left[{ }^{14} \mathrm{C}\right] \mathrm{POA}$ accumulated in the cell in the Rv1258c mutants and that of the control parent strain. It was found that the intracellular concentration of POA in Rv1258c mutants was lower than that of PZA-susceptible M. tuberculosis H37Ra (Fig. 6), indicating that PZA accumulated to a less extent in the PZA-resistant Rv1258c S292L and V219A mutants, which is an indication of higher efflux activity of the Rv1258c mutants than the parent strain. In addition, the extent of $\left[{ }^{14} \mathrm{C}\right] \mathrm{POA}$ accumulation was in accordance with the degree of resistance of the Rv1258c mutants, with the S292L mutant accumulating less POA than the V219A mutant, while both mutants accumulated less POA than the parent strain (Fig. 6B).

In conclusion, we demonstrate that point mutations in efflux pump Rv1258c found in clinical isolates can play an important role in conferring clinically relevant drug resistance to multiple drugs including PZA, SM and INH. Our findings could explain some previously unaccounted drug resistance in drug-resistant clinical strains and indicate efflux pump mutations may need to be taken into consideration for improved molecular detection of drug resistance in $M$. tuberculosis. Furthermore, efflux pump inhibitor piperine may be used as adjunct for possible more effective treatment of multi-drug resistant M. tuberculosis in future studies. 


\section{FUNDING}

This work was supported by the US-Russia (NIH-RFBR) Collaborative Research Partnership on the Prevention and Treatment of HIV/AIDS and Comorbidities grants from NIH AI108535 and AI099512, and the Russian

Foundation for Basic Research (RFBR) grant 13-04-91444.

\section{REFERENCES}

1. WHO. 2017. Global tuberculosis report.

2. Zhang Y, Yew WW. 2009. Mechanisms of drug resistance in Mycobacterium tuberculosis. Int J Tuberc Lung Dis 13:1320-30.

3. Li XZ, Nikaido H. 2009. Efflux-mediated drug resistance in bacteria: an update. Drugs 69:1555-623.

4. Liu J, Takiff HE, Nikaido H. 1996. Active efflux of fluoroquinolones in Mycobacterium smegmatis mediated by LfrA, a multidrug efflux pump. J Bacteriol 178:3791-5.

5. Ainsa JA, Blokpoel MC, Otal I, Young DB, De Smet KA, Martin C. 1998. Molecular cloning and characterization of Tap, a putative multidrug efflux pump present in Mycobacterium fortuitum and Mycobacterium tuberculosis. J Bacteriol 180:5836-43.

6. Hartkoorn RC, Uplekar S, Cole ST. 2014. Cross-resistance between clofazimine and bedaquiline through upregulation of MmpL5 in Mycobacterium tuberculosis. Antimicrob Agents Chemother 58:2979-81.

7. Andries K, Villellas C, Coeck N, Thys K, Gevers T, Vranckx L, Lounis N, de Jong BC, Koul A. 2014. Acquired resistance of Mycobacterium tuberculosis to bedaquiline. PLoS One 9:e102135.

8. K. V. Shur DAM, N. E. Mikheecheva,, N. I. Akimova OBB, and V. N. Danilenko. 2017. The Intrinsic Antibiotic Resistance to $\beta$-Lactams, Macrolides, and Fluoroquinolones of Mycobacteria Is Mediated by the whiB7 and tap Genes. Russian Journal of Genetics 53:1006-1015.

9. Ramon-Garcia S, Mick V, Dainese E, Martin C, Thompson CJ, De Rossi E, Manganelli R, Ainsa JA. 2012. Functional and genetic characterization of the tap efflux pump in Mycobacterium bovis BCG. Antimicrob Agents Chemother 56:2074-83.

10. Jiang X, Zhang W, Zhang Y, Gao F, Lu C, Zhang X, Wang H. 2008. Assessment of efflux pump gene expression in a clinical isolate Mycobacterium tuberculosis by real-time reverse transcription PCR. Microb Drug Resist 14:7-11.

11. Kanji A, Hasan R, Ali A, Zaver A, Zhang Y, Imtiaz K, Shi W, Clark TG, McNerney R, Phelan J, Rao S, Shafiq S, Hasan Z. 2017. Single nucleotide polymorphisms in efflux pumps genes in extensively drug resistant Mycobacterium tuberculosis isolates from Pakistan. Tuberculosis 107:20-30.

12. Parish T, Stoker NG. 2000. Use of a flexible cassette method to generate a double unmarked Mycobacterium tuberculosis tlyA plcABC mutant by gene replacement. Microbiology 146 ( Pt 8):196975.

13. Zhang Y, Scorpio A, Nikaido H, Sun Z. 1999. Role of acid pH and deficient efflux of pyrazinoic acid in unique susceptibility of Mycobacterium tuberculosis to pyrazinamide. J Bacteriol 181:2044-2049.

14. Zhang Y, Heym B, Allen B, Young D, Cole S. 1992. The catalase-peroxidase gene and isoniazid resistance of Mycobacterium tuberculosis. Nature 358:591-3.

15. Banerjee A, Dubnau E, Quemard A, Balasubramanian V, Um KS, Wilson T, Collins D, de Lisle G, Jacobs WR, Jr. 1994. inhA, a gene encoding a target for isoniazid and ethionamide in Mycobacterium tuberculosis. Science 263:227-30.

16. Ramon-Garcia S, Martin C, Thompson CJ, Ainsa JA. 2009. Role of the Mycobacterium tuberculosis P55 efflux pump in intrinsic drug resistance, oxidative stress responses, and growth. Antimicrob Agents Chemother 53:3675-82. 
17. Zhang Y, Mitchison D. 2003. The curious characteristics of pyrazinamide: a review. Int J Tuberc Lung Dis 7:6-21.

18. Zhang Y, Shi W, Zhang W, Mitchison D. 2014. Mechanisms of Pyrazinamide Action and Resistance. Microbiol Spectrum, ASM Press 2(4):July 2014, 2:2.4.03. doi:10.1128/microbiolspec.MGM2-00232013.

19. Shi W, Zhang X, Jiang X, Yuan H, Lee JS, Barry CE, 3rd, Wang H, Zhang W, Zhang Y. 2011. Pyrazinamide inhibits trans-translation in Mycobacterium tuberculosis. Science 333:1630-2.

20. Zhang S, Chen J, Shi W, Liu W, Zhang WH, Y Z. 2013. Mutations in panD encoding aspartate decarboxylase are associated with pyrazinamide resistance in Mycobacterium tuberculosis. Emerging Microbes \& Infections 2:e34; doi:10.1038/emi.2013.38.

21. Zhang S, Chen J, Shi W, Cui P, Zhang J, Cho S, Zhang W, Zhang Y. 2017. Mutation in clpC1 encoding an ATP-dependent ATPase involved in protein degradation is associated with pyrazinamide resistance in Mycobacterium tuberculosis. Emerg Microbes Infect 6:e8.

22. Yee M, Gopal P, Dick T. 2017. Missense Mutations in the Unfoldase ClpC1 of the Caseinolytic Protease Complex Are Associated with Pyrazinamide Resistance in Mycobacterium tuberculosis. Antimicrob Agents Chemother 61.

23. Cheng SJ, Thibert L, Sanchez T, Heifets L, Zhang Y. 2000. pncA mutations as a major mechanism of pyrazinamide resistance in Mycobacterium tuberculosis: spread of a monoresistant strain in Quebec, Canada. Antimicrob Agents Chemother 44:528-32.

24. Zhang Y, Zhang J, Cui P, Zhang W. 2017. Identification of Novel Efflux Proteins Rv0191, Rv3756c, Rv3008, and Rv1667c Involved in Pyrazinamide Resistance in Mycobacterium tuberculosis. Antimicrob Agents Chemother 61.

25. Sharma S, Kumar M, Nargotra A, Koul S, Khan IA. 2010. Piperine as an inhibitor of Rv1258c, a putative multidrug efflux pump of Mycobacterium tuberculosis. J Antimicrob Chemother 65:1694-701. 
bioRxiv preprint doi: https://doi.org/10.1101/249102; this version posted January 17,2018 . The copyright holder for this preprint (which was not certified by peer review) is the author/funder, who has granted bioRxiv a license to display the preprint in perpetuity. It is made available under aCC-BY-NC-ND 4.0 International license.

Э3 drugs

34

35

36

37

38

39

30

J1

32

33

)4

J5

36

37

38

9

10

11

\begin{tabular}{|c|c|c|}
\hline \multirow{2}{*}{ Drugs } & \multicolumn{2}{|c|}{ Drug susceptibility results\# } \\
\hline & Rv1258c V219A & Rv1258c S292L \\
\hline Isoniazid & $\mathrm{R}(\mathrm{MIC} 0.125 \mu \mathrm{g} / \mathrm{ml})$ & $\mathrm{R}(\mathrm{MIC} 32 \mu \mathrm{g} / \mathrm{ml})$ \\
\hline Pyrazinamide & $\mathrm{R}(\mathrm{MIC} 100 \mu \mathrm{g} / \mathrm{ml})$ & $\mathrm{R}(\mathrm{MIC} 800 \mu \mathrm{g} / \mathrm{ml})$ \\
\hline Streptomycin & S & $\mathrm{R}(\mathrm{MIC} 4.0 \mu \mathrm{g} / \mathrm{ml})$ \\
\hline Rifampin & $\mathrm{S}$ & $\mathrm{S}$ \\
\hline Ethambutol & $S$ & $S$ \\
\hline Amikacin & $\mathrm{S}$ & $\mathrm{S}$ \\
\hline Cycloserine & S & S \\
\hline p-aminosalicylic acid (PAS) & S & $\mathrm{S}$ \\
\hline Clofazimine & $\mathrm{S}$ & $\mathrm{S}$ \\
\hline Tetracycline & $\mathrm{S}$ & $S$ \\
\hline Linezolid & S & $\mathrm{S}$ \\
\hline Clarithromycin & $\mathrm{S}$ & $\mathrm{S}$ \\
\hline
\end{tabular}

\# S indicates "susceptible"; $\mathrm{R}$ indicates "resistant". Red color indicate resistance conferred by Rv1258c point mutations S292L or V219A 
bioRxiv preprint doi: https://doi org/10.1101/249102 this version posted January 17,2018 . The copyright holder for this preprint (which was not certified by peer review) is the author/funder, who has granted bioRxiv a license to display the preprint in perpetuity. It is made available under aCC-BY-NC-ND 4.0 International license. 


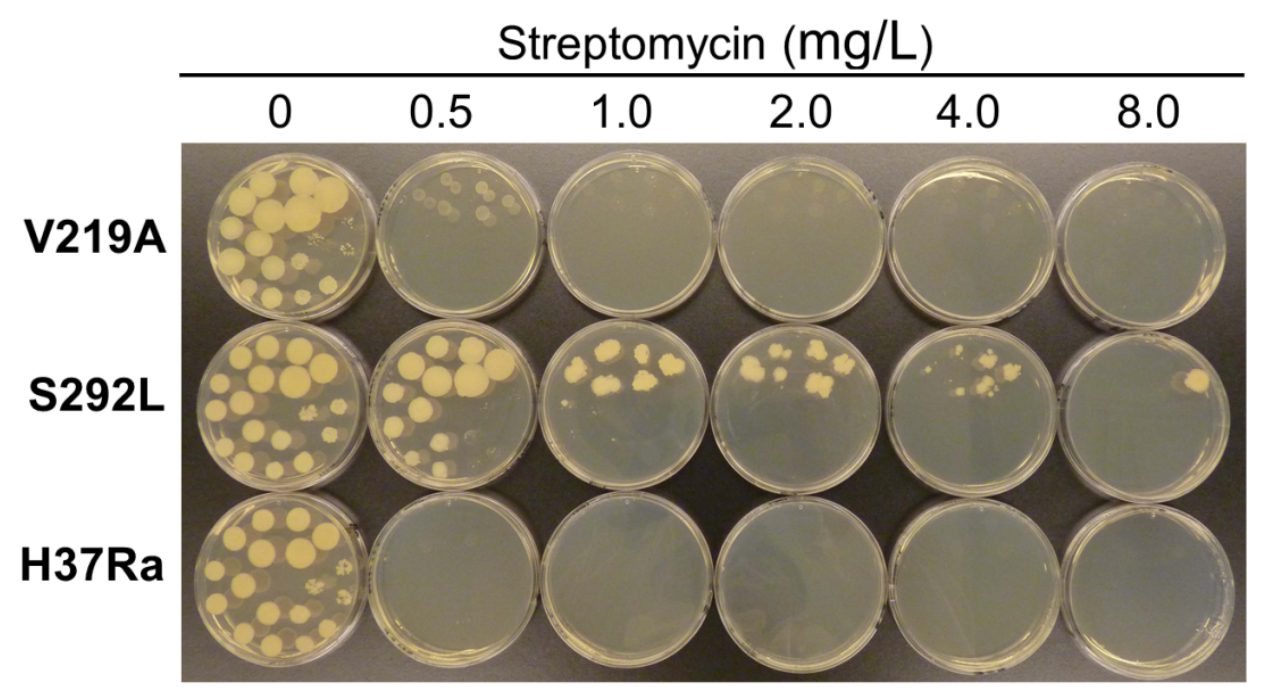

Figure 1. The Rv1258c S292L mutant has higher level of resistance to streptomycin than

The V219 mutant.

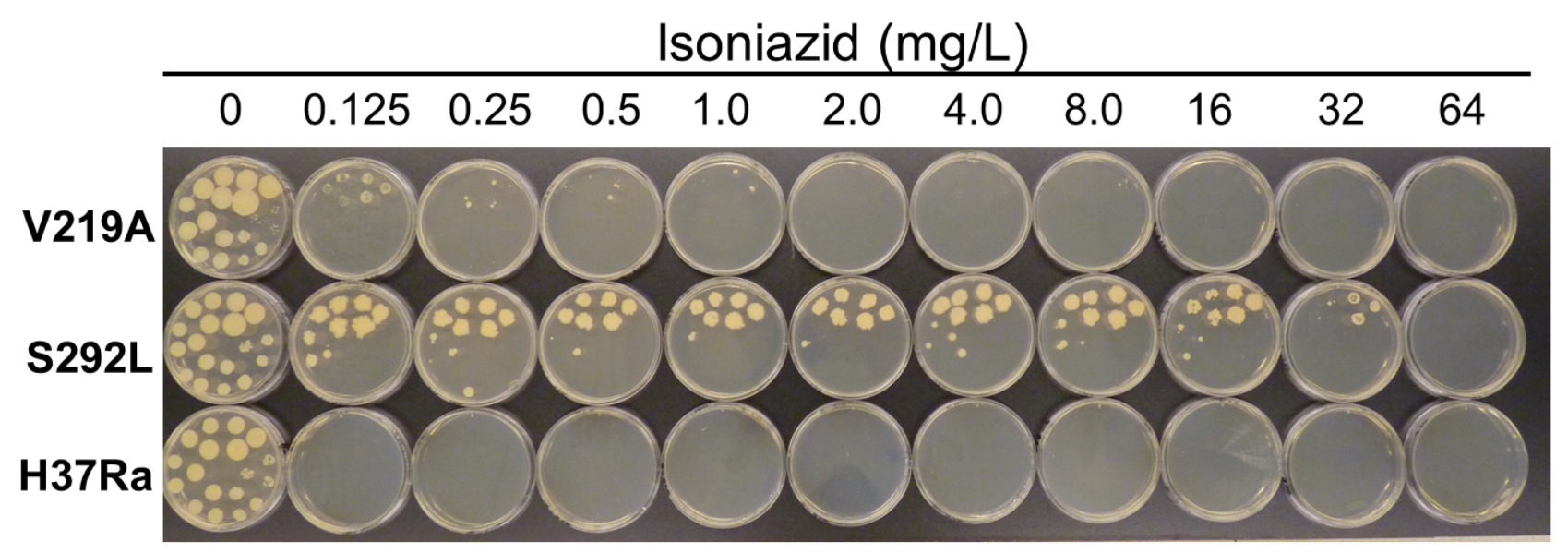

Figure 2. The Rv1258c S292L mutant is highly resistant to isoniazid, while the V219A mutant is only slightly resistant. 


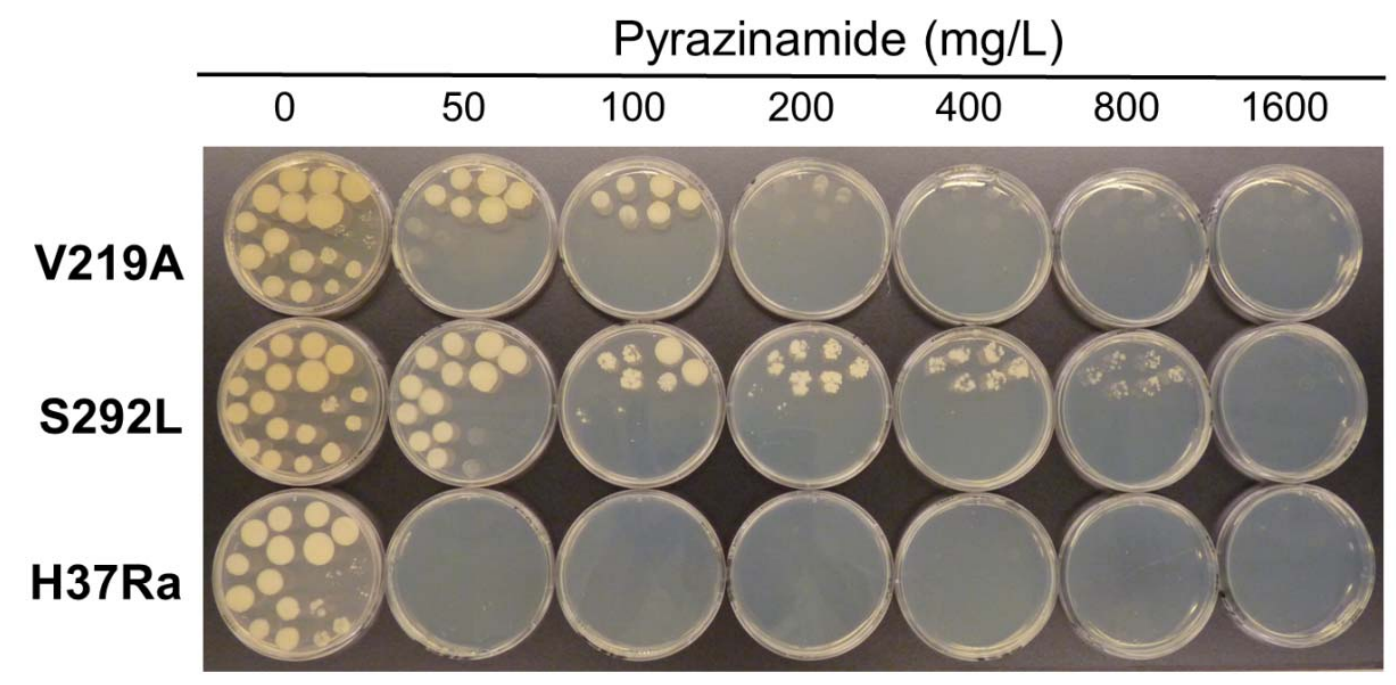

Figure 3. The Rv1258c S292L mutant has a higher level of PZA resistance than the V219A mutant.

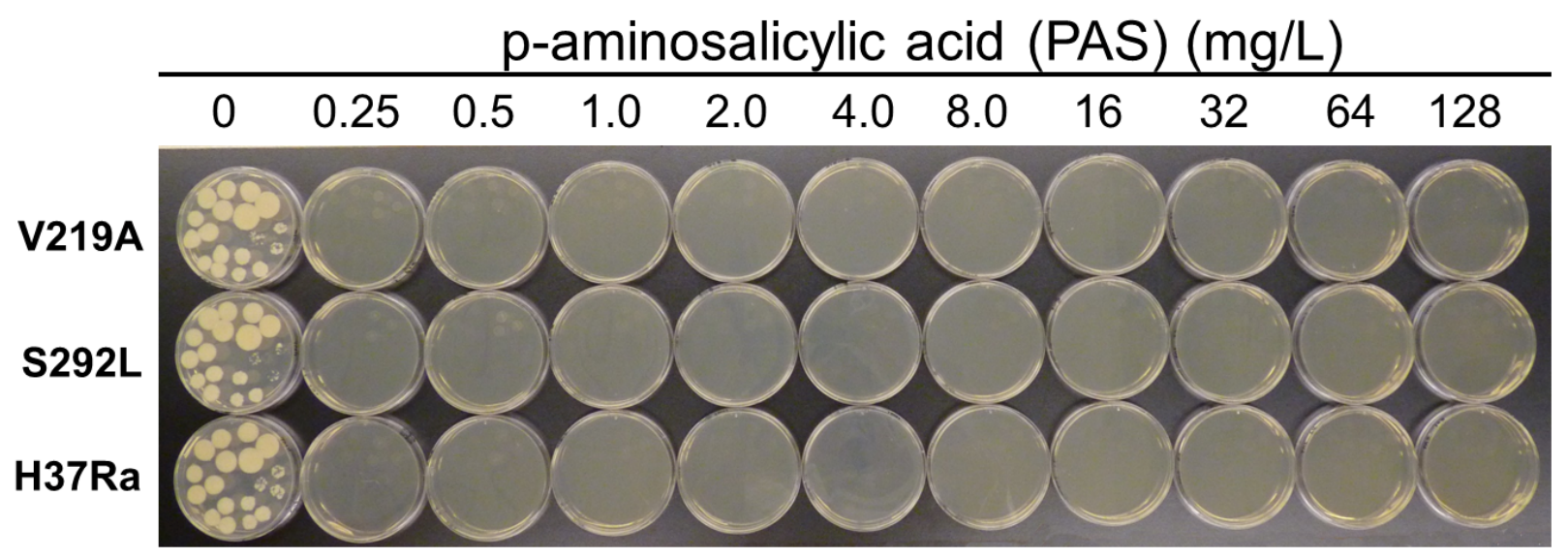

Figure 4. The Rv1258c S292L and V219A mutants remain susceptible to PAS. 
bioRxiv preprint doi: https://doi.org/10.1101/249102; this version posted January 17,2018 . The copyright holder for this preprint (which was not certified by peer review) is the author/funder, who has granted bioRxiv a license to display the preprint in perpetuity. It is made available under aCC-BY-NC-ND 4.0 International license.

A

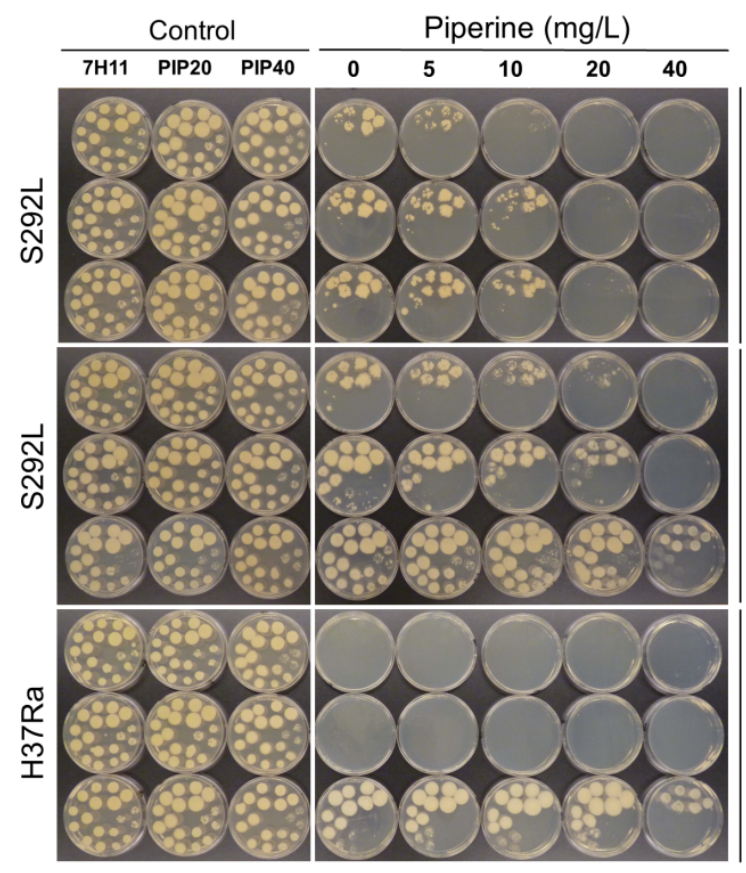

B

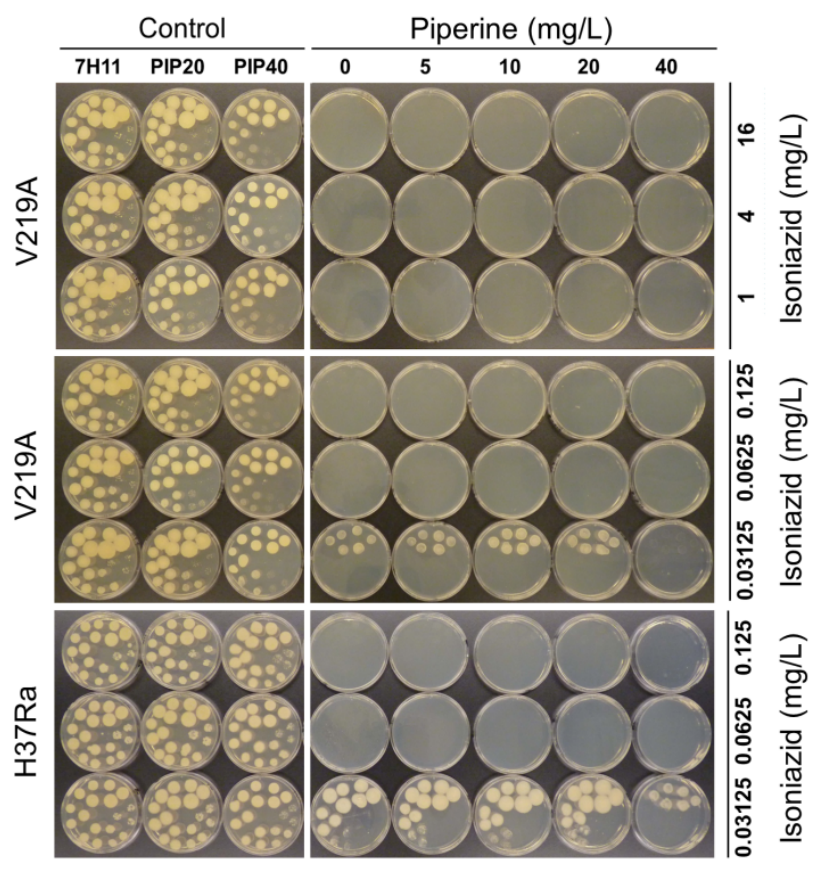

C

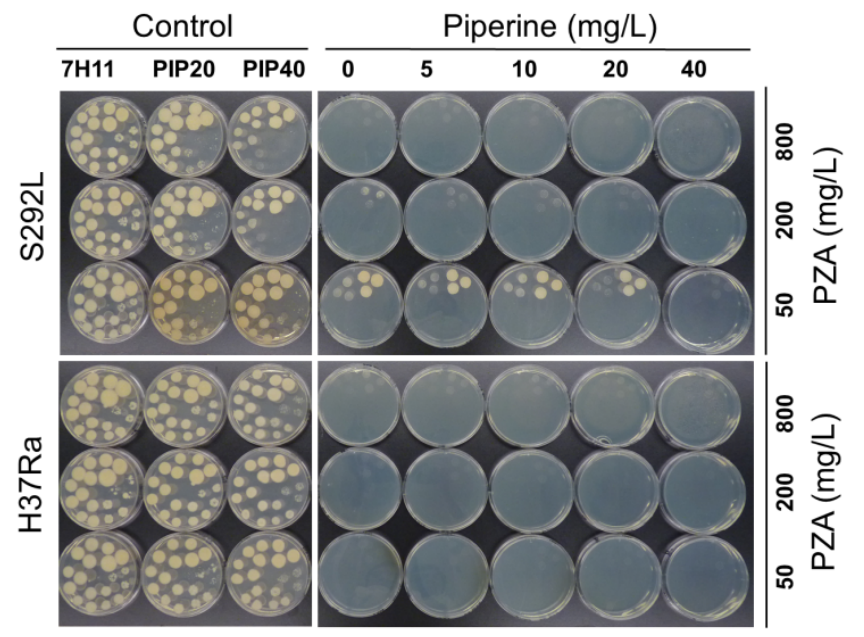

Figure 5. Piperine inhibited the INH (A) and PZA resistance (C) resistance in the Rv1258c S292L mutant, but not in the V219A mutant (B). 
A Time (min)

Time (hour)

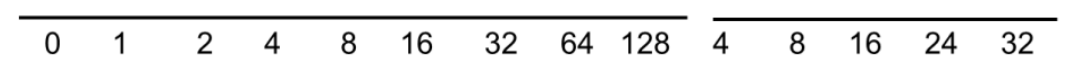

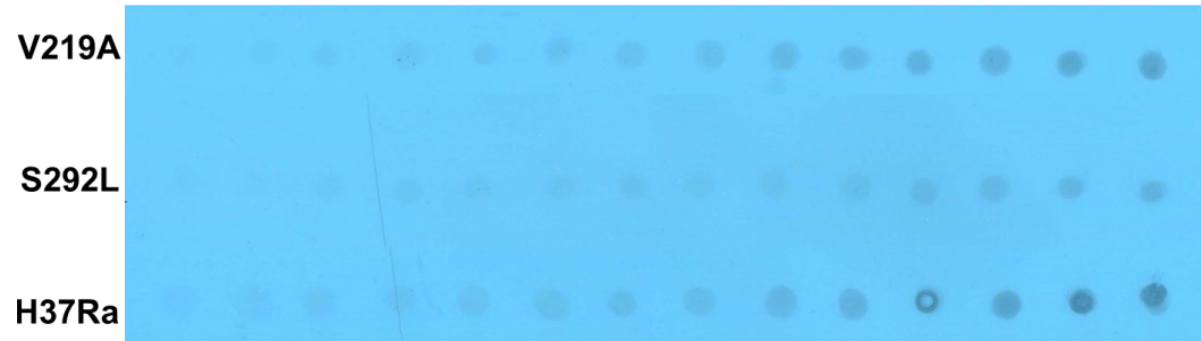

B

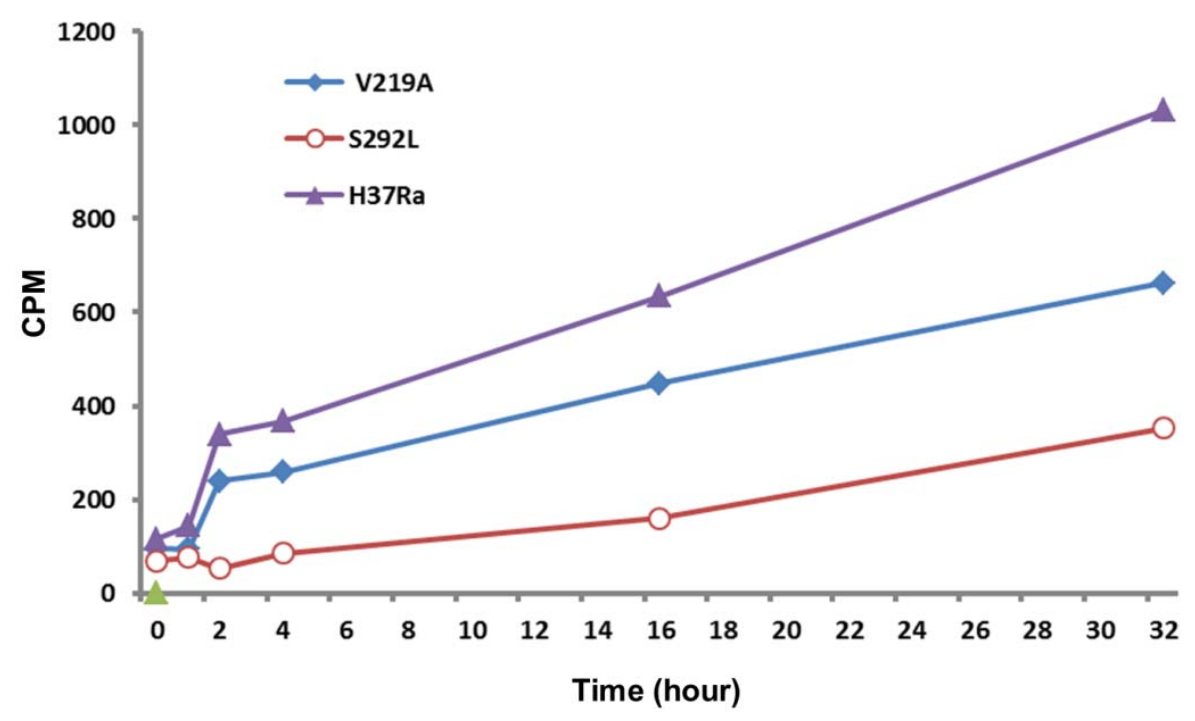

Figure 6. Comparison of PZA/POA accumulation in Rv1258c mutants. $\left[{ }^{14} \mathrm{C}\right] \mathrm{PZA}$ was added to $5 \times 10^{9}$ M. tuberculosis $\mathrm{H} 37 \mathrm{Ra}$ at a concentration of $1 \mu \mathrm{Ci} / \mathrm{ml}$ at $\mathrm{pH}$ 6.6. At different times after PZA addition, portions of bacterial cells were removed and washed by filtration using phosphate buffered saline ( $\mathrm{pH}$ 6.6) as described in Methods. The results of PZA/POA accumulation are shown by autoradiography (A) and scintillation counting (B). The S292L mutant accumulated 
bioRxiv preprint doi: https://doi.org/10.1101/249102; this version posted January 17,2018 . The copyright holder for this preprint (which was not certified by peer review) is the author/funder, who has granted bioRxiv a license to display the preprint in perpetuity. It is made available under aCC-BY-NC-ND 4.0 International license.

less drug than the V219A mutant, while both mutants accumulated less drug than the parent strain M. tuberculosis H37Ra. 